1989-6

\title{
Development, Simulation, and Validation of a Highly Nonlinear Hydraulic Servosystem Model
}

\author{
Tim W. McLain \\ University of Utah Center for Engineering Design, mclain@byu.edu \\ E K. Iversen \\ University of Utah Center for Engineering Design \\ C C. Davis \\ University of Utah Center for Engineering Design \\ S C. Jacobsen \\ University of Utah Center for Engineering Design
}

Follow this and additional works at: https://scholarsarchive.byu.edu/facpub

Part of the Mechanical Engineering Commons

\section{Original Publication Citation}

McLain, T., Iversen, E., Davis, C., and Jacobsen, S. Development, Simulation, and Validation of a Highly Nonlinear Hydraulic Servo System Model, Proceedings of the 1989 American Control Conference, pp. 385-391, June 1989, Pittsburgh, Pennsylvania.

\section{BYU ScholarsArchive Citation}

McLain, Tim W.; Iversen, E K.; Davis, C C.; and Jacobsen, S C., "Development, Simulation, and Validation of a Highly Nonlinear Hydraulic Servosystem Model" (1989). Faculty Publications. 2107.

https://scholarsarchive.byu.edu/facpub/2107

This Peer-Reviewed Article is brought to you for free and open access by BYU ScholarsArchive. It has been accepted for inclusion in Faculty Publications by an authorized administrator of BYU ScholarsArchive. For more information, please contact ellen_amatangelo@byu.edu. 
Presented at the 1989 American Control Conference. June 21-23, 1989, Pittsburgh, Pennsylvania.

\title{
Development, Simulation, and Validation of a Highly Nonlinear Hydraulic SERvosystem Model
}

\author{
T.W. McLain, E.K. Iversen, C.C. Davis, S.C. Jacobsen \\ Center for Engineering Design \\ University of Utah \\ Salt Lake City, Utah 84112
}

\begin{abstract}
A highly accurate and predictive dynamic model of an electrohydraulic actuation system has been developed and verified. The accuracy of the model can be attributed to the inclusion of nonlinear representations of many system elements including hysteresis and saturation effects, orifice areas, piston damping, and flow forces. This level of accuracy makes the model a potentially valuable tool in the analysis and design of electrohydraulic actuation systems.
\end{abstract}

\section{INTRODUCTION}

In recent years, applications such as aerospace, robotics, and computer storage media have pushed actuator performance to its limits. It has become clear to investigators that improvements in such advanced systems depend not merely on the development of clever control algorithms, but also on the understanding and design of high performance actuators with intrinsic behaviors that are closely matched to their intended application.

A significant amount of research effort has been directed toward understanding the dynamic characteristics of hydraulic servosystems through the use of mathematical models. The majority of past work has focused on the modeling of twostage, four-way, spool-type servovalves. In much of the earlier work, linear transfer function based models were used [1-3]. In more recent work, Shearer [4-5] performed time domain simulations of a hydraulic servomechanism using a model which employed nonlinear valve characteristics and Coulomb-type friction in the actuator.

The work presented in this paper differs from previous work in two ways. First, the actuation system under consideration uses a single-stage, four-way, suspension-type valve with dynamic characteristics that differ significantly from those of two-stage spool valves. Secondly, a large number of nonlinearities and modeling elements have been included in the model to ensure a high degree of correlation between the performance of the model and that of the real system. This paper focuses on the development and verification of the actuator model, while a forthcoming paper [6] details the sensitivity of actuator performance characteristics to changes in various system parameters.

\section{MODEL DESCRIPTION}

\section{System Description}

The hydraulic actuator model formulated was based upon an actuator design developed at the Center for Engineering Design (CED) at the University of Utah. The actuator under consideration consists of a single-stage, four-way, suspension valve coupled to a linear piston actuator (see Figure 1).

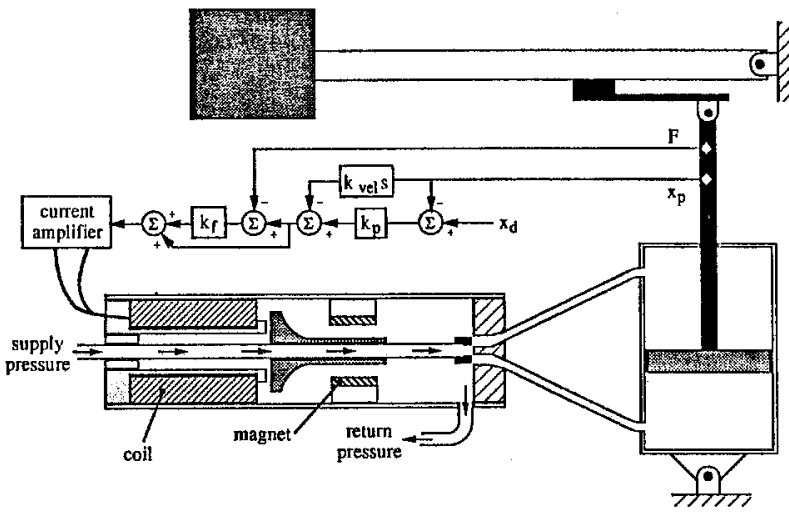

Figure 1. Schematic of Hydraulic Actuation System.

Current commands to the torque motor of the valve modulate the position of the valve pipe tip, which serves to meter the areas of the supply and return orifices to each side of the piston actuator. The actuator is connected to the load via a compliant member with internal damping and damping to ground. A bond graph model of the actuator system was formulated from the actuator hardware and is shown in Figure 2. From this graphical representation, equations modeling the dynamic response of the system were derived.

\section{Actuator Bond Graph Model}

The third-order lumped parameter model for the valve includes the inductance $\left(\mathrm{I}_{\mathrm{e}}\right)$, the resistance $\left(\mathrm{R}_{\mathrm{e}}\right)$, and the torque constant (B) for the motor portion of the valve, as well as the mass $\left(m_{v}\right)$, stiffness $\left(k_{v}\right)$, and damping $\left(b_{v}\right)$ of the valve pipe. Experimentation during the development of the valve demonstrated the existence of forces on the valve pipe tip due to the momentum of the fluid flowing through the orifices. These forces are represented by the element $\mathrm{F}_{\mathrm{Q}}$ in the bond graph model. Tests of the valve torque motor also showed that hysteresis in the motor armature had a significant effect on valve performance. The modeling of these nonlinear effects will be discussed in detail in following sections. The value of valve pipe stiffness $\left(\mathrm{k}_{\mathrm{v}}\right)$ used in the model includes the effect of the magnetic field on the armature, which in essence reduces the mechanical stiffness of the cantilevered valve pipe.

The modeling of the hydraulic portion of the valve/actuator was complex because of the large number of lumped parameters and nonlinear relations involved. The parameters used to describe the system can be outlined as follows: $P_{s}$ and $P_{I}$ represent the supply and return pressures respectively; elements $I_{f s}$ and $I_{f r}$ model the fluid inertance in the supply and return lines to the valve; fitting losses and line losses in the supply and return lines are modeled by elements $R_{1 s}$ and $R_{1 r}$; 
the compliance of the supply and return lines is represented by elements $\mathrm{C}_{1 s}$ and $\mathrm{C}_{\mathrm{lr}}$; elements $\mathrm{C}_{\mathrm{f} 1}$ and $\mathrm{C}_{\mathrm{f} 2}$ model the fluid compressibility and line compliance on each side of the piston; fluid inertance in lines from the valve to the piston is modeled

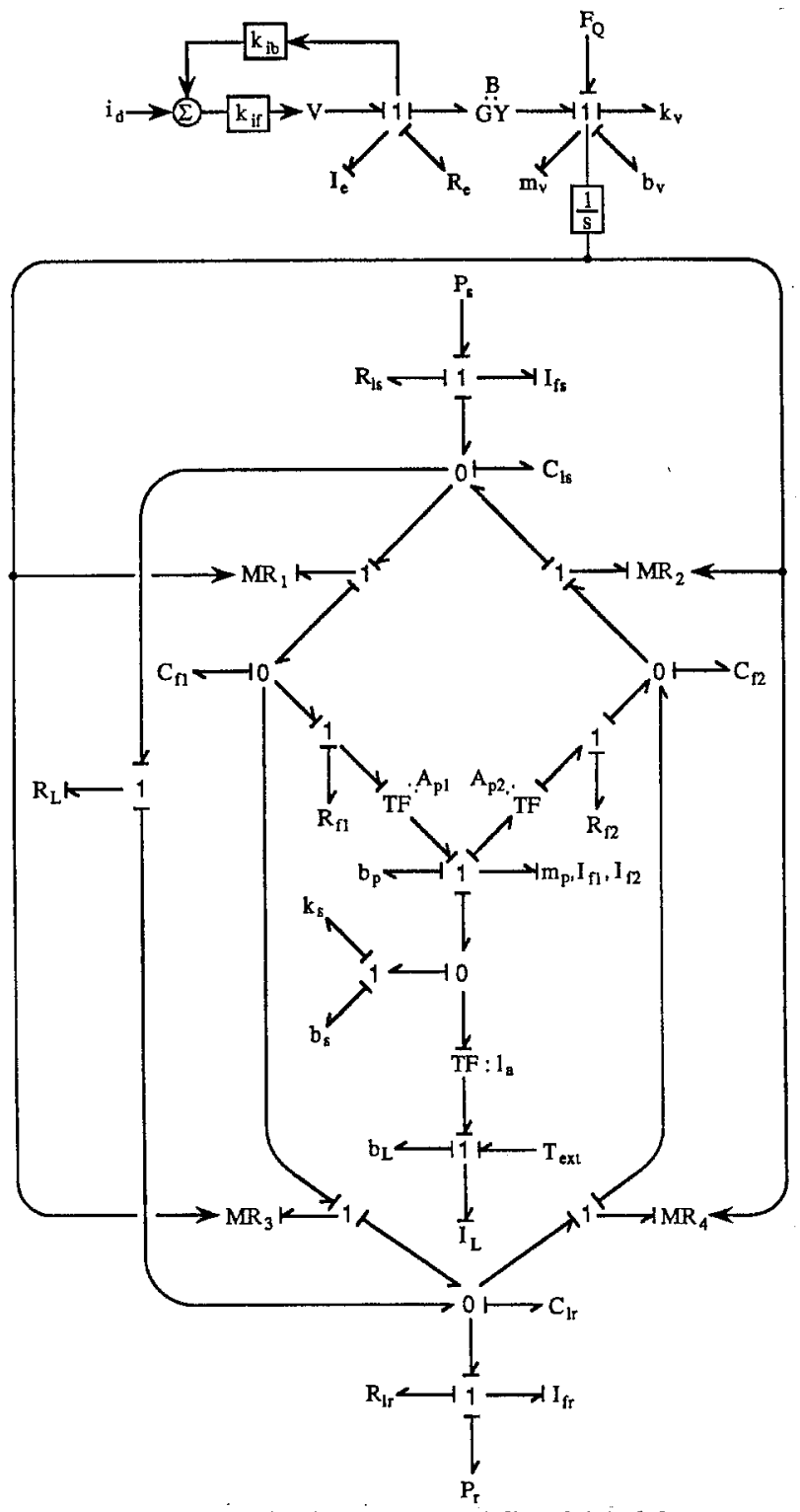

Figure 2. Actuator Bond Graph Model. by elements $I_{f 1}$ and $I_{f 2}$; similarly, fitting and line losses between the valve and the piston are modeled by elements $R_{f 1}$ and $R_{f 2} ; m_{p}$ represents the piston mass, while $b_{p}$ models the nonlinear Coulombic and viscous friction in the piston; $A_{p 1}$ and $A_{p 2}$ represent the 'piston areas; element $R_{L}$ represents leakage from the supply side to the return side of the valve; the pressure flow relationships for the metered orifices of the valve are modeled by elements $M R_{1}, M R_{2}, M R_{3}$, and $M R_{4}$. The more complicated constitutive relations for these elements are described as functions of the fundamental system parameters in equations 1 to 5 below.

$$
\begin{array}{ll}
\text { Element } & \begin{array}{l}
\text { Constitutive Relation } \\
I_{f s}, I_{f r}, I_{f 1}, I_{f 2}
\end{array} \\
C_{l s}, C_{l r} & P=\frac{\rho l}{A_{1}} \dot{Q} \\
C_{f 1}, C_{f 2} & Q=\frac{V_{l d}}{E t_{w}} \dot{P} \\
R_{1 s}, R_{l r}, R_{f 1}, R_{f 2} & P=\frac{128 \mu 1}{\pi d^{4}} Q+\frac{(\Sigma k) \rho}{2 A_{l}^{2}} Q^{2} \\
M R_{1}, M R_{2}, M R_{3}, M R_{4}, R_{L} & Q=C_{d} A \operatorname{sgn}(\Delta P) \sqrt{\frac{2|\Delta P|}{\rho}}
\end{array}
$$

The compliant member connecting the piston and the load is modeled by parallel spring and damping elements $\left(k_{s}, b_{s}\right)$ which allow modeling of structural oscillations between the actuator and the load. The load consists of a mass $\left(\mathrm{m}_{\mathrm{L}}\right)$, an external force disturbance $\left(\mathrm{F}_{\mathrm{ext}}\right)$, and a damper $\left(\mathrm{b}_{\mathrm{L}}\right)$ connected to ground.

\section{Nonlinear Elements}

Hysteresis and Saturation. To achieve the level of accuracy of simulation desired, the effects of hysteresis and saturation in the valve motor were included in the model. Simulation of saturation effects presents little difficulty when using one of the many dynamic simulation software packages available. Conversely, hysteresis proved to be more difficult to model accurately. A variation of the algorithm developed by Frame, et al. [7] was implemented with one exception. The hysteresis in the actuator model was modeled by calculating motor torque as a function of current, whereas in [7], hysteresis was considered in terms of flux linkages as a function of current. This technique provides for accurate modeling of both major and minor hysteresis loops under transient conditions. Further details of the modeling of these effects will be given in the verification section of the paper.

Flow Forces. In the valve design under consideration, flow forces due to fluid momentum on the valve pipe tip

\footnotetext{
Nomenclature

$A_{1}, A_{2}, A_{3}, A_{4}, A_{L}=$ orifice and leakage areas

$A_{p 1}, A_{p 2}=$ piston areas

$b_{v}, b_{p}, b_{s}, b_{g}=$ valve, piston, structural, and load damping

$\mathrm{B}=$ motor torque and back EMF constant

$\mathrm{c}=$ clearance between valve pipe tip and receiver plate

$\mathrm{C}_{\mathrm{ds}}, \mathrm{C}_{\mathrm{dr}}, \mathrm{C}_{\mathrm{L}}=$ supply, return, and leakage discharge coefficients

$\mathrm{d}, \mathrm{A}_{\mathrm{l}}, \mathrm{t}_{\mathrm{w}},=$ line diameter, cross-sectional area, and wall thickness

$\mathrm{E}=$ line elastic modulus

$\mathrm{F}_{\mathrm{Q}}=$ flow forces on valve pipe tip

$i_{s}, i_{d}=$ actual and desired valve current

$\mathrm{I}_{\mathrm{e}}, \mathrm{R}_{\mathrm{e}}=$ electrical inductance and resistance

$\mathrm{I}_{\mathrm{L}}=$ inertia of load

$\mathrm{k}_{\mathrm{ib}}, \mathrm{k}_{\mathrm{if}}, \mathrm{k}_{\mathrm{p}}, \mathrm{k}_{\mathrm{f}}, \mathrm{k}_{\mathrm{vel}}=$ control gains

$k_{\mathrm{V}}, \mathbf{k}_{\mathrm{s}}=$ valve and structural stiffness

$\mathrm{l}_{\mathrm{a}}=$ crank moment arm length

$1_{S}, l_{r}, 1_{1}, l_{2}=$ supply, return, and actuator line lengths
}

$\mathrm{m}_{\mathrm{v}}, \mathrm{m}_{\mathrm{p}}=$ valve and piston mass

$\mathrm{P}_{\mathrm{f} 1}, \mathrm{P}_{\mathrm{f}}=$ piston chamber pressures

$\mathrm{P}_{\mathrm{Ls}}, \mathrm{P}_{\mathrm{Lr}}=$ supply and return line pressures

$\mathrm{P}_{\mathrm{S}}, \mathrm{P}_{\mathrm{r}}=$ supply and return pressures

$\mathrm{Q}_{\mathrm{S}}, \mathrm{Q}_{\mathrm{T}}=$ supply and return line flow

$I=$ orifice radius

$\mathrm{T}_{\text {ext }}=$ external torque disturbance

$\mathrm{u}_{\mathrm{S}}, \mathrm{u}_{\mathrm{T}}=$ underlapping on supply and return orifices

$\mathrm{V}_{\mathrm{f} 1}, \mathrm{~V}_{\mathrm{f} 2}=$ piston chamber fluid volumes

$V_{\text {is }}, V_{\mathrm{lr}}=$ supply and return line fluid volumes

$V_{11}, V_{12}=$ actuator line fluid volumes

$v_{v}, v_{p}, v_{L}=$ valve, piston, and load velocities

$\mathrm{x}_{\mathrm{v}}, \mathrm{x}_{\mathrm{d}}, \mathrm{x}_{\mathrm{p}}, \mathrm{x}_{\mathrm{L}}=$ valve, desired piston, piston, and load positions

$\rho, \mu, \beta=$ fluid density, viscosity, and bulk modulus

$\theta_{L}, \omega_{L}=$ angular position and velocity of load

$\Sigma \mathbf{k}_{\mathrm{s}}, \boldsymbol{\Sigma}_{\mathrm{I}}=$ supply and return line fitting loss coefficients 
dramatically affect valve stability. Similar flow force phenomena for other types of valve designs have been documented in the literature [8]. Experimentation with the suspension-type valve has shown flow forces to be functions of flow through the orifices and displacement of the valve from the null position. Equation 6 below shows the flow

$$
F_{Q}=k_{Q} \frac{Q_{1}+Q_{2}+Q_{3}+Q_{4}}{\sqrt{\left|x_{v}\right|+k_{1}}}
$$

force formulation implemented in the valve model where $\mathrm{k}_{\mathrm{Q}}$ and $\mathrm{k}_{1}$ are experimentally obtained constants. Although a rigorous analysis was not performed to substantiate this formulation, reasonably good correlation between the model and experimental results support the validity of this implementation.

Piston Damping. Coulombic and viscous friction effects in the piston seals were modeled as Figure 3 shows below.

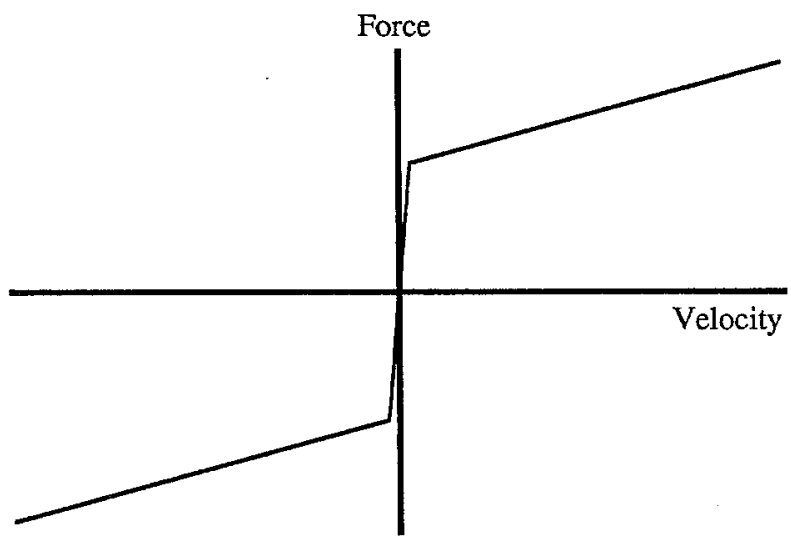

Figure 3. Piston Friction Nonlinearity.

Qrifice Areas. A schematic showing the orifice areas for the valve design under consideration is shown in Figure 4. The equations for the orifice areas were derived from equations describing the area of a segment of a circle as a function of its fundamental dimensions. The equations are quite complicated because they allow variable port diameters and lapping, and because clearance between the valve pipe tip and receiver plate is incorporated into the area relations. Equations 7 to 11 show the orifice area relations for each of the two supply and two return orifices and the leakage.

Orifice 1

$$
\begin{aligned}
& \text { for } x_{v}<-u_{s}, \quad A_{1}=A_{L 1} \\
& \text { for }-u_{s}<x_{v}<2 r-u_{s}, \\
& A_{1}=A_{L 1}+\frac{r}{c} A_{L 1}-4\left(2 r-x_{v}-u_{s}\right) \sqrt{r\left(x_{v}+u_{s}\right)-\left(\frac{x_{v}+u_{s}}{2}\right)^{2}} \\
& \quad \text { where } A_{L 1}=8 r c \cos ^{-1}\left(\frac{2 r-x_{v}-u_{s}}{2 r}\right)
\end{aligned}
$$

\section{Orifice 2}

for $x_{v}>u_{s}, \quad A_{2}=A_{L 2}$

for $-2 \mathrm{r}+\mathrm{u}_{\mathrm{s}}<\mathrm{x}_{\mathrm{v}}<\mathrm{u}_{\mathrm{s}}$,

$A_{2}=A_{L 2}+\frac{r}{c} A_{L 2}-4\left(2 r+x_{v}-u_{s}\right) \sqrt{r\left(u_{s}-x_{v}\right)-\left(\frac{u_{s}-x_{v}}{2}\right)^{2}}$

$$
\text { where } A_{L 2}=8 r c \cos ^{-1}\left(\frac{2 r+x_{v}-u_{s}}{2 r}\right)
$$

Orifice 3

$$
\begin{aligned}
& \text { for } x_{v}>u_{r}, \quad A_{3}=A_{L 3} \\
& \text { for }-2 r+u_{r}<x_{V}<u_{r}, \\
& A_{3}=A_{L 3}-4\left(r+x_{V}-u_{r}\right) \sqrt{2 r\left(u_{r}-x_{v}\right)-\left(u_{r}-x_{V}\right)^{2}} \\
& \quad+4 r^{2} \cos ^{-1}\left(\frac{r+x_{V}-u_{I}}{r}\right) \\
& \text { where } A_{L 3}=8 r c \cos ^{-1}\left(\frac{-2 r+x_{V}+u_{s}}{2 r}\right)
\end{aligned}
$$

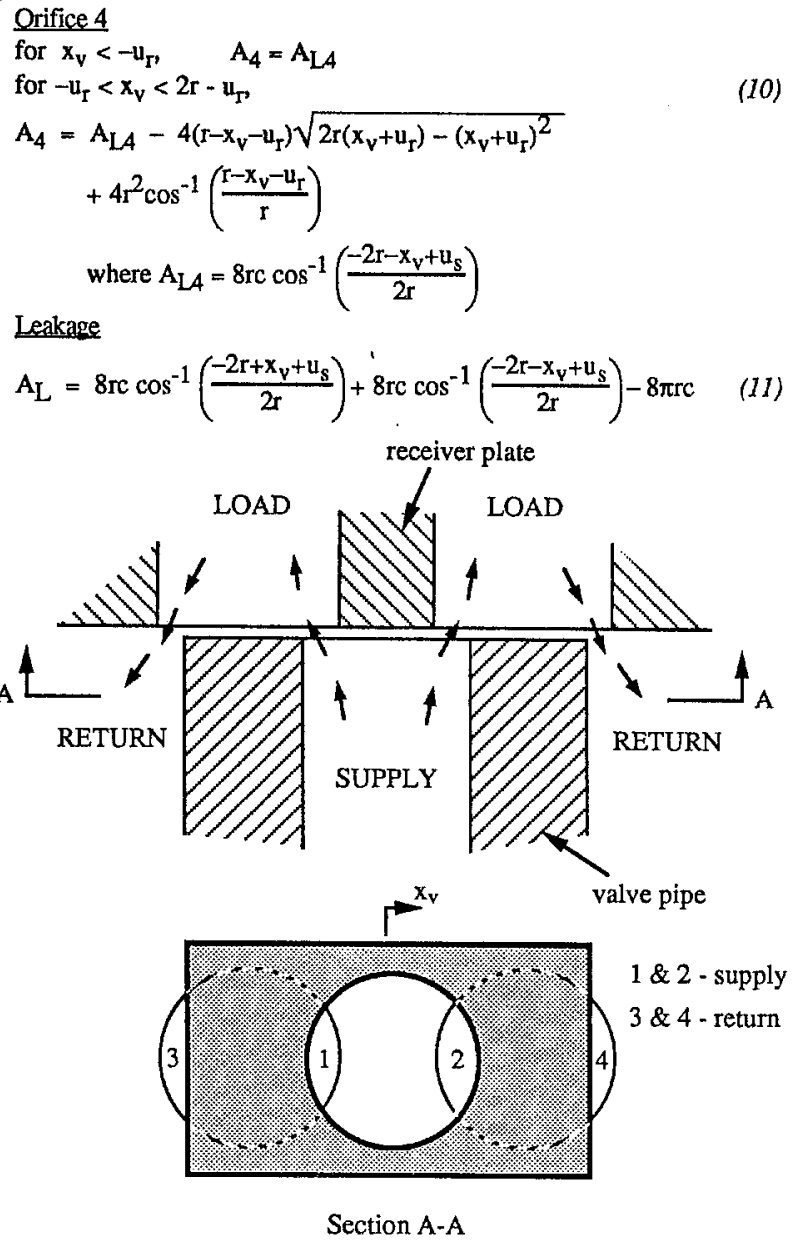

Figure 4. Orifice Area Schematic.

\section{Control Structure}

The simple linear control structure included in the model consists of three feedback loops: 1) an inner force feedback loop modulated by gain $\mathrm{k}_{\mathrm{f}}$ to feed back the force in the compliant member; 2) a velocity feedback loop modulated by gain $\mathrm{k}_{\mathrm{vel}}$ which carries the piston velocity signal; and 3 ) an outer position feedback loop modulated by gain $\mathrm{k}_{\mathrm{p}}$ to feed back the piston position signal. The input to the system is desired position $\left(\mathrm{x}_{\mathbb{d}}\right)$ and the system output is the position of the piston $\left(x_{p}\right)$. Equation 12 gives the mathematical representation of the control law. Figure 1 shows an implementation of this control structure with the hydraulic actuation system under investigation.

$$
i_{d}=\left(1+k_{f}\right)\left(k_{p}\left(x_{d}-x_{p}\right)-k_{v e l} v_{p}\right)-k_{f}\left(k_{s}\left(x_{p}-x_{L}\right)+b_{s}\left(v_{p}-v_{L}\right)\right)
$$

\section{Modeling Assumptions}

In the development of the actuation system model, a number of simplifying assumptions have been made:

1) Valve damping is linear and the valve is critically damped in the open loop.

2) Supply and return pressure sources are ideal and do not fluctuate in time.

3) Flow in the lines is laminar (linear flow-line loss relationship).

4) Fluid compressibility and line compliance effects are linear. This holds for relatively small pressure fluctuations from the steady state pressure and for small expansions in the lines.

5) Orifice and leakage flows are correctly modeled by the signed quadratic relation between pressure and flow. 
6) In defining fluid inertance, the momentum of the fluid on the inlet and outlet sides of the control volume are assumed to be the same.

7) Damping and stiffness components in the flexible member are linear. This assumption is valid for small deflections in the structure.

8) There is no significant leakage past the piston.

Model verification results indicate that these assumptions are valid.

\section{System Equations}

From the bond graph model and constitutive relations outlined above, the equations of motion for the hydraulic actuator system were derived. The set of thirteen first-order nonlinear differential equations obtained are listed below (equations 13 to 25 ).

\section{Valve Equations}

$\dot{i}_{s}=\frac{1}{\mathrm{I}_{e}}\left(\mathrm{k}_{\mathrm{if}}\left(\mathrm{i}_{\mathrm{d}}-\mathrm{k}_{\mathrm{ib}} \dot{\mathrm{i}}_{\mathrm{s}}\right)-\mathrm{R}_{\mathrm{e}} \mathrm{i}_{\mathrm{s}}-B\left(\mathrm{v}_{\mathrm{v}}\right)\right)$

$\dot{\mathrm{v}}_{\mathrm{v}}=\frac{1}{\mathrm{~m}_{\mathrm{v}}}\left(B\left(\mathrm{i}_{\mathrm{S}}\right)-\mathrm{b}_{\mathrm{v}} \mathrm{v}_{\mathrm{v}}-\mathrm{k}_{\mathrm{v}} \mathrm{x}_{\mathrm{v}}-\mathrm{F}_{\mathrm{Q}}\right)$

$\dot{\mathrm{x}}_{\mathrm{y}}=\mathrm{v}_{\mathrm{v}}$

\section{Actuator-Load Equations}

$$
\begin{aligned}
& \dot{\mathrm{Q}}_{\mathrm{S}}=\frac{\mathrm{A}_{\mathrm{l}}}{\rho \mathrm{l}_{\mathrm{s}}}\left(\mathrm{P}_{\mathrm{s}}-\frac{128 \mu \mathrm{l}_{\mathrm{s}}}{\pi \mathrm{d}^{4}} \mathrm{Q}_{\mathrm{s}}+\frac{\left(\Sigma \mathrm{k}_{\mathrm{s}}\right) \rho}{2 \mathrm{~A}_{\mathrm{l}}{ }^{2}} \mathrm{Q}_{\mathrm{s}}{ }^{2} \mathrm{sgn}\left(\mathrm{Q}_{\mathrm{s}}\right)-\mathrm{P}_{\mathrm{Ls}}\right) \\
& \dot{\mathrm{P}}_{\mathrm{Ls}}=\frac{\mathrm{Et}_{\mathrm{w}}}{\mathrm{V}_{\mathrm{Ls}} \mathrm{d}}\left(\mathrm{Q}_{\mathrm{s}}-\mathrm{C}_{\mathrm{dL}} \mathrm{A}_{\mathrm{L}} \operatorname{sgn}\left(\mathrm{P}_{\mathrm{Ls}}-\mathrm{P}_{\mathrm{Lr}}\right) \sqrt{\frac{2\left|\mathrm{P}_{\mathrm{Ls}}-\mathrm{P}_{\mathrm{LT}}\right|}{\rho}}\right. \\
& -C_{d s} A_{1} \operatorname{sgn}\left(P_{L s}-P_{f 1}\right) \sqrt{\frac{2\left|P_{L s}-P_{f 1}\right|}{p}} \\
& \left.-C_{d s} A_{2} \operatorname{sgn}\left(P_{L s}-P_{f 2}\right) \sqrt{\frac{2\left|P_{L s}-P_{\mathrm{f} 2}\right|}{p}}\right) \\
& \dot{\mathrm{P}}_{\mathrm{f} 1}=\left(\frac{\mathrm{V}_{\mathrm{L} 1} \mathrm{~d}}{\mathrm{Et}_{\mathrm{w}}}+\frac{\mathrm{V}_{\mathrm{f} 1}+\mathrm{V}_{\mathrm{L1}}}{\beta}\right)^{-1}\left(\mathrm{C}_{\mathrm{ds}} \mathrm{A}_{1} \operatorname{sgn}\left(\mathrm{P}_{\mathrm{Ls}}-\mathrm{P}_{\mathrm{f} 1}\right) \sqrt{\frac{2\left|\mathrm{P}_{\mathrm{Ls}}-\mathrm{P}_{\mathrm{f} 1}\right|}{\rho}}\right. \\
& \left.-A_{p 1} v_{p}+C_{d r} A_{3} \operatorname{sgn}\left(P_{L r}-P_{f 1}\right) \sqrt{\frac{2\left|P_{L r}-P_{f 1}\right|}{\rho}}\right) \\
& \dot{\mathrm{P}}_{\mathrm{f} 2}=\left(\frac{\mathrm{V}_{\mathrm{L} 2} \mathrm{~d}}{\mathrm{Et}_{\mathrm{w}}}+\frac{\mathrm{V}_{\mathrm{f} 2}+\mathrm{V}_{\mathrm{L} 2}}{\beta}\right)^{-1}\left(\mathrm{C}_{\mathrm{dr}} \mathrm{A}_{4} \operatorname{sgn}\left(\mathrm{P}_{\mathrm{Lr}}-\mathrm{P}_{\mathrm{f} 2}\right) \sqrt{\frac{2\left|\mathrm{P}_{\mathrm{Lr}}-\mathrm{P}_{\mathrm{f} 2}\right|}{\rho}}\right. \\
& \left.+A_{p 2} v_{p}+C_{d s} A_{2} \operatorname{sgn}\left(P_{L s}-P_{f 2}\right) \sqrt{\frac{2\left|P_{L s}-P_{f 2}\right|}{\rho}}\right) \\
& \dot{v}_{p}=\left(m_{p}+\frac{\rho}{A_{1}}\left(1_{1} A_{p 1}^{2}+1_{2} A_{p 2}^{2}\right)\right)^{-1}-k_{s}\left(x_{p}-x_{L}\right)+b_{s}\left(v_{p}-v_{L}\right) \\
& -b_{p}\left(\mathrm{v}_{\mathrm{p}}\right)+A_{\mathrm{p} 1}\left(\mathrm{P}_{\mathrm{f} 1}-\frac{128 \mu \mathrm{l}_{1}}{\pi \mathrm{d}^{4}} \mathrm{~A}_{\mathrm{pl}} \mathrm{v}_{\mathrm{p}}-\frac{\left(\Sigma \mathrm{k}_{\mathrm{T}}\right) \rho}{2 \mathrm{~A}^{2}}\left(\mathrm{~A}_{\mathrm{pl}} \mathrm{v}_{\mathrm{p}}\right)^{2} \operatorname{sgn}\left(\mathrm{v}_{\mathrm{p}}\right)\right) \\
& -A_{p 2}\left(P_{f 2}-\frac{128 \mu l_{2}}{\pi d^{4}} A_{p 2} v_{p}-\frac{\left(\Sigma_{k_{f}}\right) \rho}{2 A^{2}}\left(A_{p 2} v_{p}\right)^{2} \operatorname{sgn}\left(v_{p}\right)\right) \\
& \dot{\mathrm{x}}_{\mathrm{p}}=\mathrm{v}_{\mathrm{p}} \\
& \dot{\omega}_{\mathrm{L}}=\frac{1}{\mathrm{I}_{\mathrm{L}}}\left(\left[\mathrm{k}_{\mathrm{s}}\left(\mathrm{x}_{\mathrm{p}}-\mathrm{x}_{\mathrm{L}}\right)+\mathrm{b}_{\mathrm{s}}\left(\mathrm{v}_{\mathrm{p}}-\mathrm{v}_{\mathrm{L}}\right)\right] \cos \theta_{\mathrm{L}}-\mathrm{b}_{\mathrm{g}} \omega_{\mathrm{L}}+\mathrm{T}_{\mathrm{ext}}\right) \\
& \text { where } x_{L}=1_{a} \sin \theta_{L} \text { and } v_{L}=\omega_{L} l_{a} \cos \theta_{L} \\
& \dot{\theta}_{\mathrm{L}}=\omega_{\mathrm{L}} \\
& \dot{\mathrm{P}}_{\mathrm{Lr}}=\frac{\mathrm{Et}_{\mathrm{w}}}{\mathrm{V}_{\mathrm{L}} \mathrm{d}^{\mathrm{d}}}\left(\mathrm{C}_{\mathrm{dL}} \mathrm{A}_{\mathrm{L}} \operatorname{sgn}\left(\mathrm{P}_{\mathrm{Ls}}-\mathrm{P}_{\mathrm{Lr}}\right) \sqrt{\frac{2\left|\mathrm{P}_{\mathrm{Ls}}-\mathrm{P}_{\mathrm{Lr}}\right|}{\rho}}\right. \\
& -\mathrm{C}_{\mathrm{dr}} \mathrm{A}_{4} \operatorname{sgn}\left(\mathrm{P}_{\mathrm{Lr}}-\mathrm{P}_{\mathrm{f} 2}\right) \sqrt{\frac{2\left|\mathrm{P}_{\mathrm{Lr}}-\mathrm{P}_{\mathrm{f} 2}\right|}{\rho}} \\
& \left.-C_{d r} A_{3} \operatorname{sgn}\left(P_{L r}-P_{f 1}\right) \sqrt{\frac{2\left|P_{L T}-P_{f 1}\right|}{\rho}}-Q_{r}\right)
\end{aligned}
$$

$\dot{\mathrm{Q}}_{\mathrm{r}}=\frac{\mathrm{A}_{1}}{\rho \mathrm{l}_{\mathrm{r}}}\left(\mathrm{P}_{\mathrm{Lr}}-\mathrm{P}_{\mathrm{r}}-\frac{128 \mu \mathrm{l}_{\mathrm{r}}}{\pi \mathrm{d}^{4}} \mathrm{Q}_{\mathrm{r}}-\frac{\left(\Sigma \mathrm{R}_{\mathrm{r}}\right) \rho}{2 \mathrm{~A}_{\mathrm{l}}^{2}} \mathrm{Q}_{\mathrm{r}}^{2} \mathrm{sgn}\left(\mathrm{Q}_{\mathrm{I}}\right)\right)$

\section{MODEL VERIFICATION}

The model verification for the hydraulic actuator system was carried out in essentially three steps: 1) taking step response data from an actual hydraulic actuator test system; 2) performing a computer simulation of equations of motion obtained from the actuator model; and 3) adjusting estimated model parameters until a good correlation between the model data and test data was achieved. These steps are outlined in the following sections.

\section{Test Apparatus and Instrumentation}

A hydraulic actuator test apparatus was fabricated for the specific purpose of verifying the computer model that had been developed. One of the primary objectives in the design of the test apparatus was to provide a method for varying as many of the system parameters as possible. Parameters, such as the fluid line dimensions, the compliant member stiffness, and the mass of the load, were adjustable over wide ranges.

An effort was made to instrument as many of the system states as possible. This was accomplished with the exception of valve pipe tip velocity and supply and return line flow rates. In addition to the system states, the force in the compliant member was also measured. Sensor signals were conditioned with analog circuitry and recorded using a digital data acquisition system.

\section{Computer Simulation}

The equations and nonlinearities outlined in the first portion of this paper were coded into the ACSL simulation language [9]. Gear's stiff integration method proved to be the most efficient of the algorithms available for solving the differential equations. Each simulation required approximately 26.5 CPU seconds on a VAXstation II computer.

\section{Verification Method}

Verification was performed by setting the values of the computer model parameters to values corresponding to those of the test system. Parameters that could be measured directly (load mass, fluid line length, valve pipe stiffness, etc.) were measured. A number of parameters were measured indirectly. Valve pipe damping and load damping, for example, were calculated from gain/phase and logarithmic decay measurements. Other parameter values were determined from handbooks and manufacturer's specifications (fluid density, fluid viscosity, fluid line elastic modulus, etc.). Several parameters, such as orifice coefficients of discharge, could not be measured and were estimated.

Valve Model Verification. The most difficult part of the system to model was the valve because of the number of nonlinearities: hysteresis, saturation, flow forces, and orifice and leakage areas. Hysteresis and saturation characteristics were measured for the test valve by inputting sinusoidal current signals to the valve and measuring the corresponding valve tip position. This data was then implemented directly into the model. Figures 5-7 show comparisons of model data and test data at three different frequencies. Similar tests were performed to develop the simple flow force model described in the first part of the paper. The orifice area portion of the model was verified by modulating the valve tip position and measuring the flow to the load and leakage flow. Fine adjustments were made to values of orifice underlap and discharge coefficients to achieve better correlation between the model and test data.

System Model Verification. To validate the system model, a step input of equal magnitude to that given to the test system was applied to the model. Initial conditions of the model states were set to correspond with those of the test system. Major 


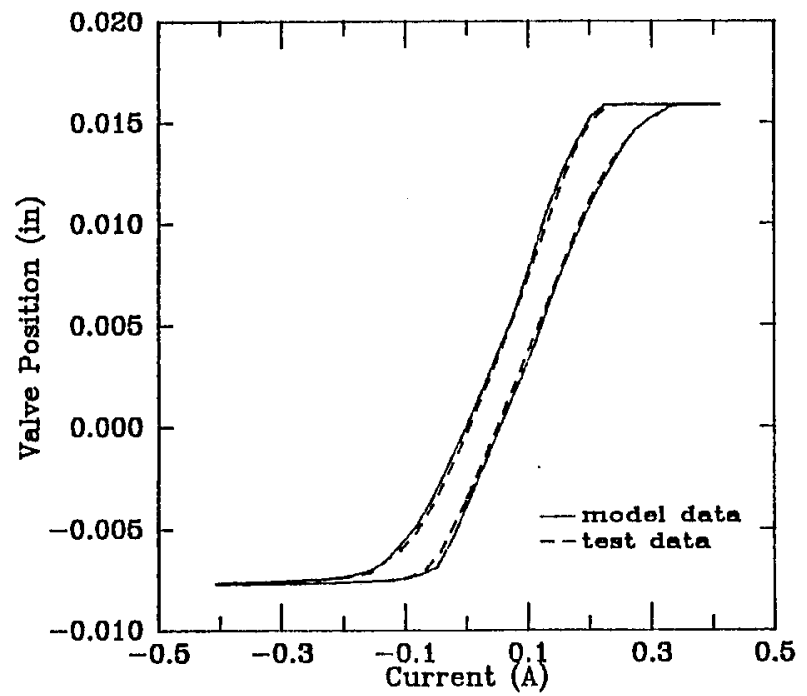

Figure 5. Valve Position vs. Current -- $0.105 \mathrm{~Hz}$.

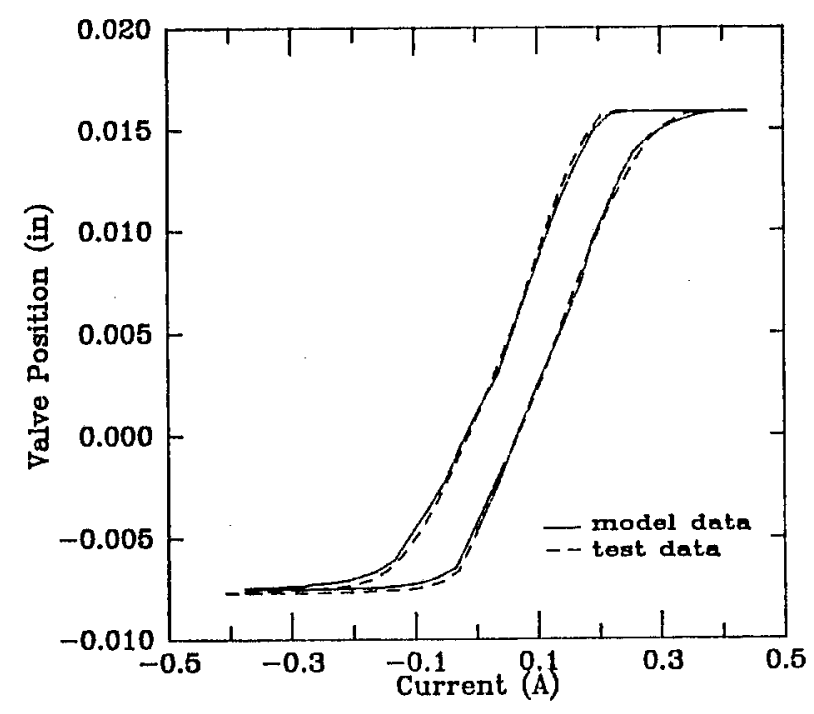

Figure 6. Valve Position vs. Current $-1.08 \mathrm{~Hz}$.

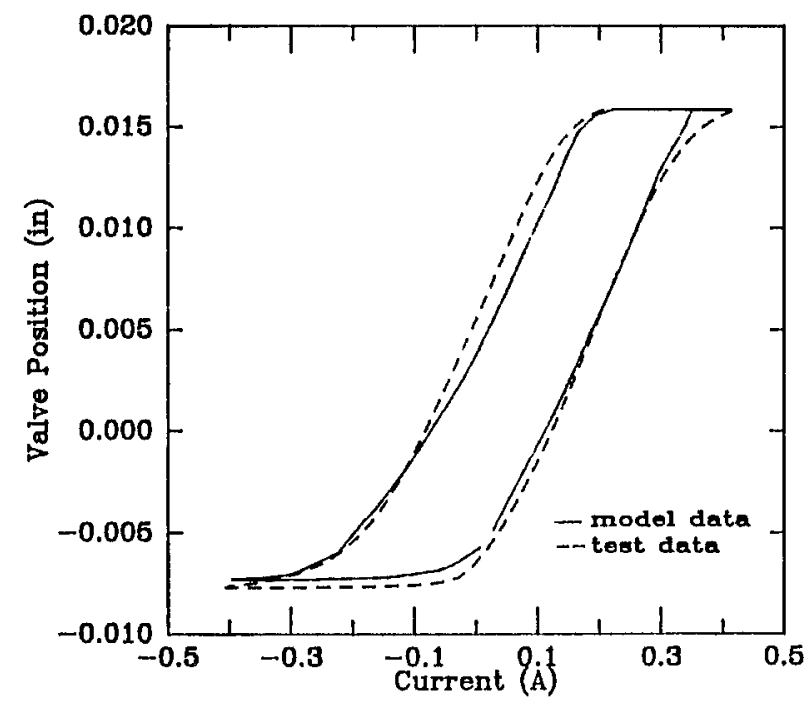

Figure 7. Valve Position vs. Current $-6.30 \mathrm{~Hz}$. differences between the simulation results and test data due to modeling. and simulation errors were found at several stages during the verification procedure. Through an iterative process of simulating, comparing results, and debugging, the more obvious of the errors were eliminated.

\section{RESULTS}

By fine tuning the estimated parameters of the model, a very good correlation between the model data and the test data for current input (Figure 8), valve position (Figure 9), piston position (Figure 10), load position (Figure 12), load velocity (Figure 13), and force in the compliant member (Figure 14) was achieved. Good correlation between model and test data for the current input and valve position was expected due to the high level of detail of the model and the use of actual valve data to formulate the valve model. The relative simplicity of the compliant member and load portion of the system allowed accurate modeling of that portion of the system. The time delay between the values of measured and modeled piston velocity (Figure 11) was due to the filtering of the differentiated piston position signal that was used as a measure of the actual piston velocity. Discrepancies between model and test data for the pressures on each side of the piston (Figures 15 and 16) can be attributed to assumptions of linear fluid and line

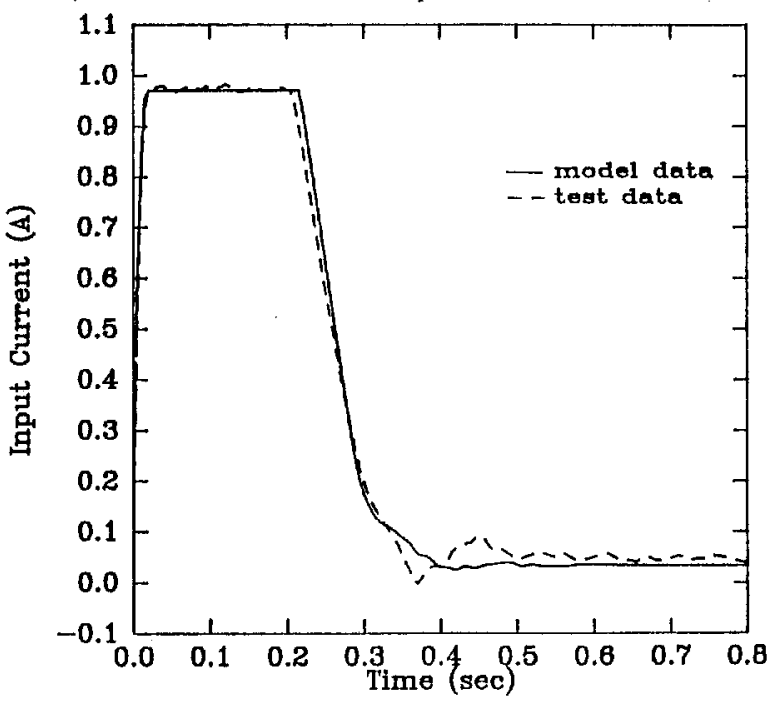

Figure 8. Input Current vs. Time.

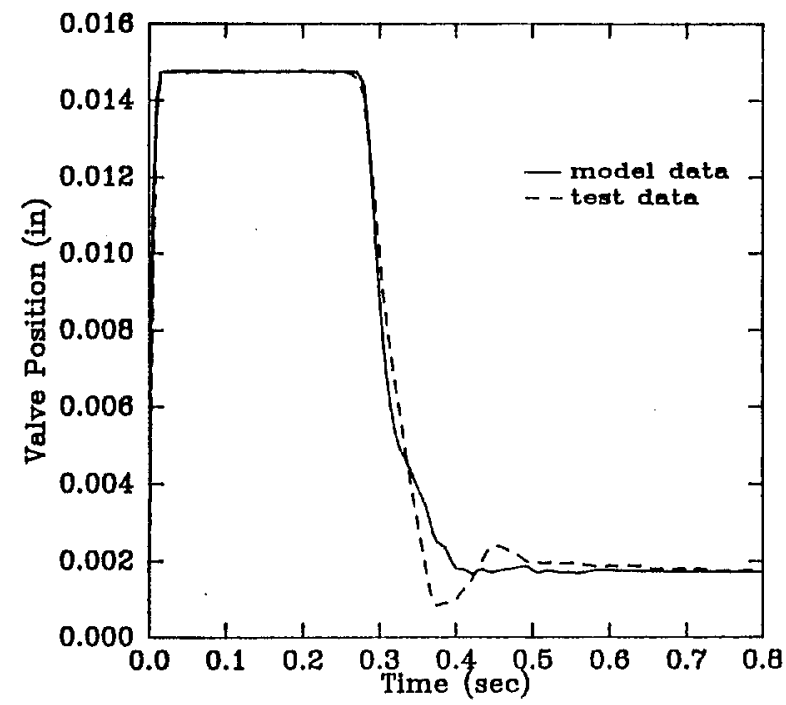

Figure 9. Valve Position vs. Time. 


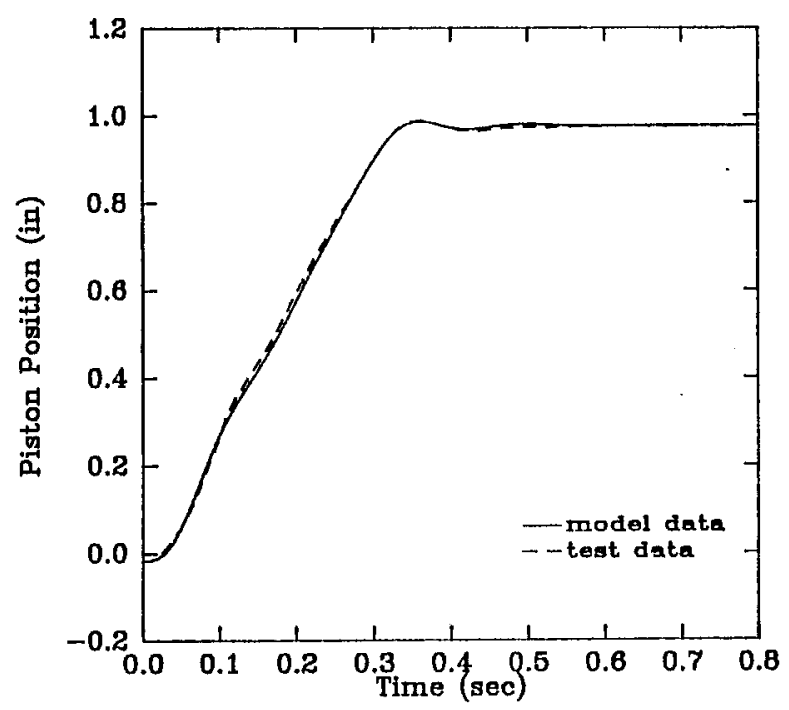

Figure 10. Piston Position vs. Time.

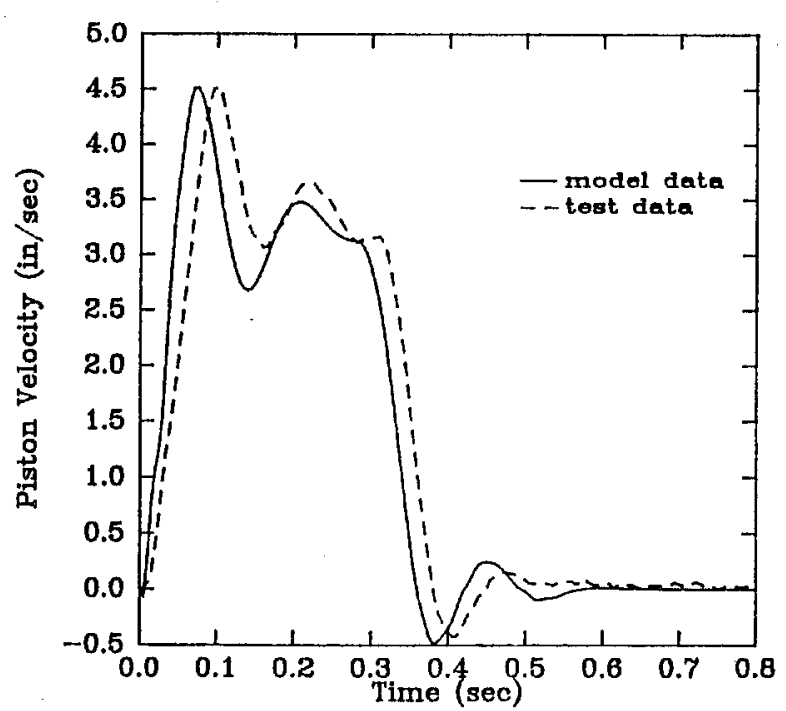

Figure 11. Piston Velocity vs. Time.

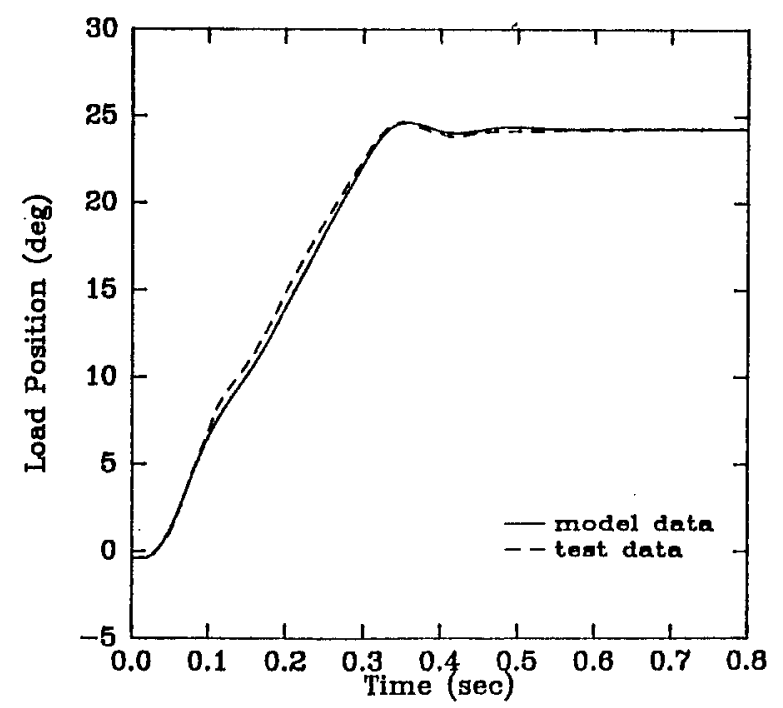

Figure 12. Load Position vs. Time.

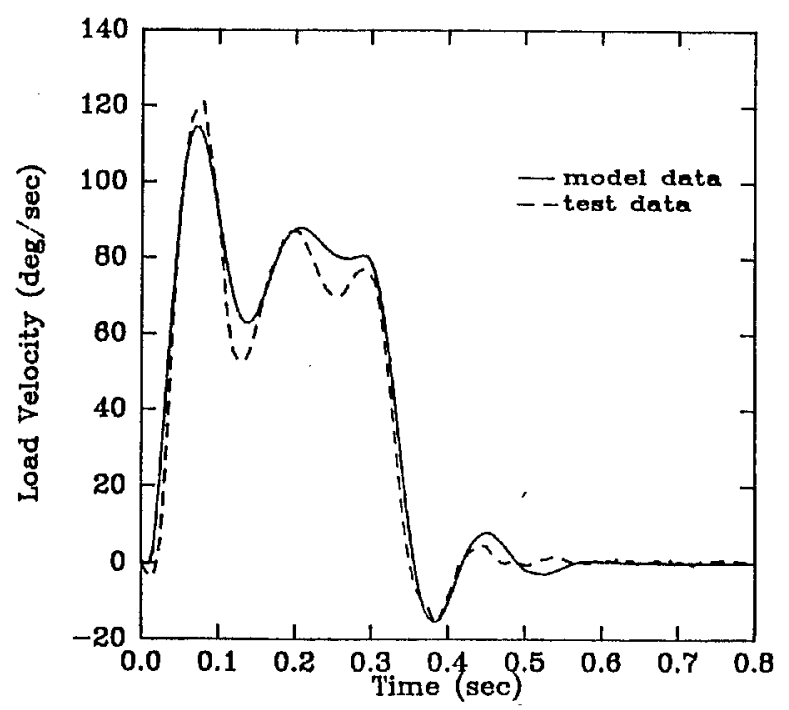

Figure 13. Load Velocity vs. Time.

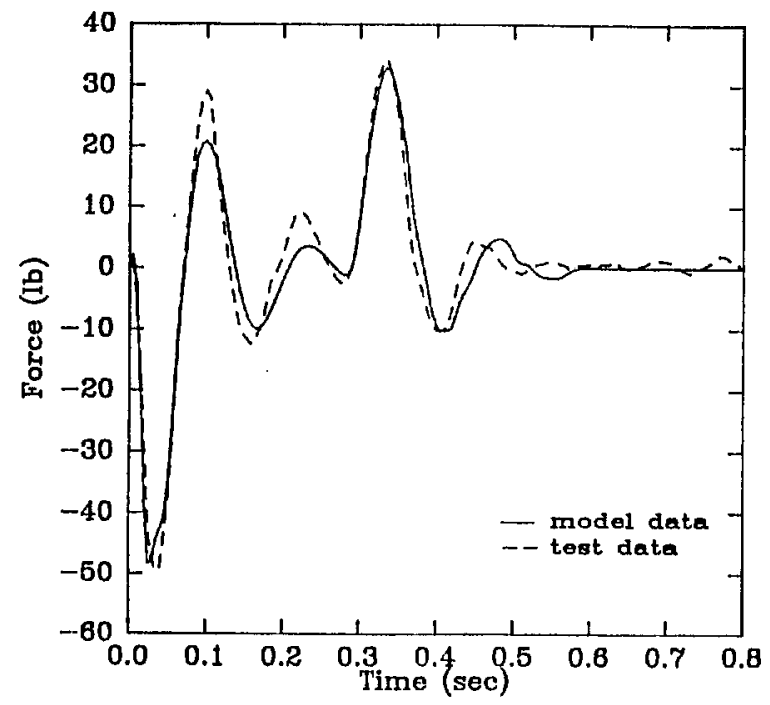

Figure 14. Force in the Structural Member vs. Time.

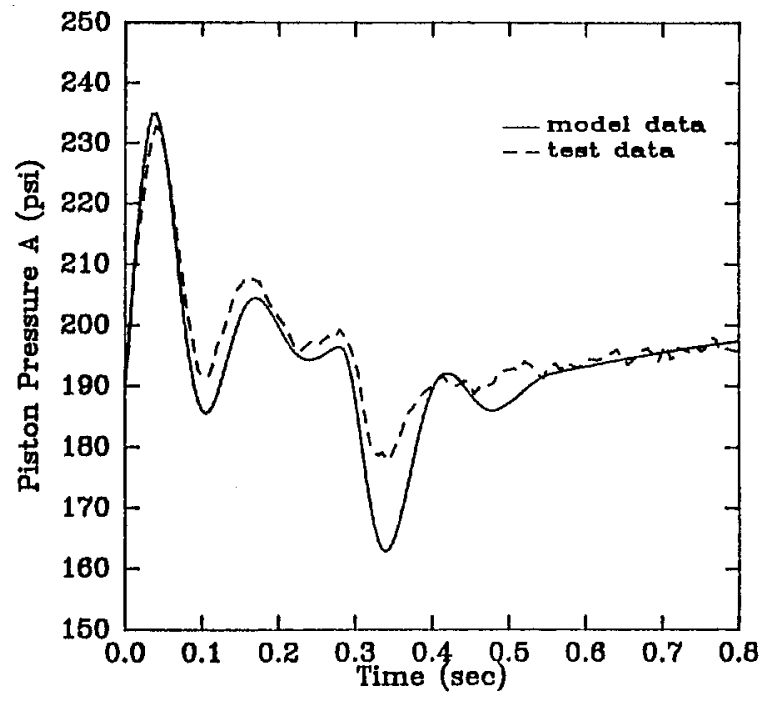

Figure 15. Piston Pressure A vs. Time. 


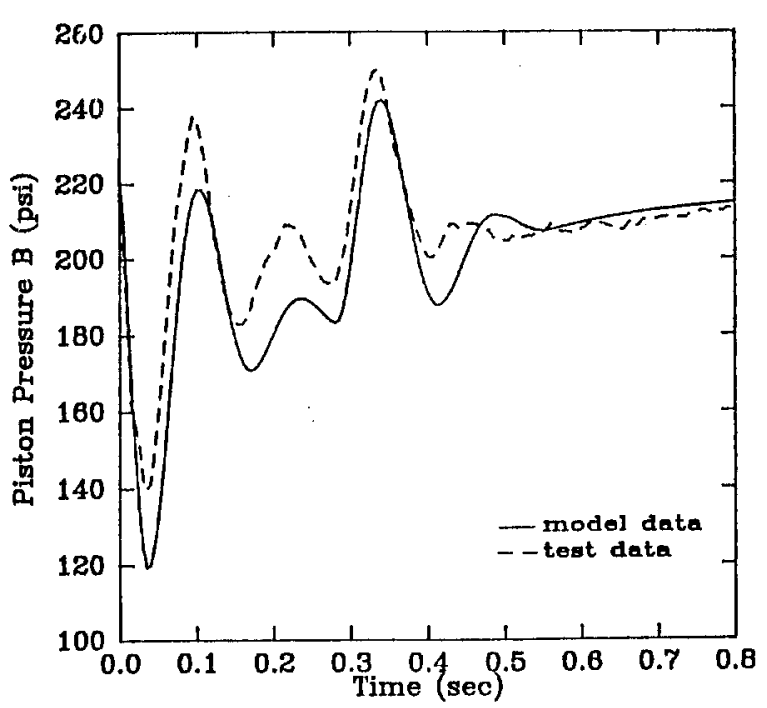

Figure 16. Piston Pressure B vs. Time.

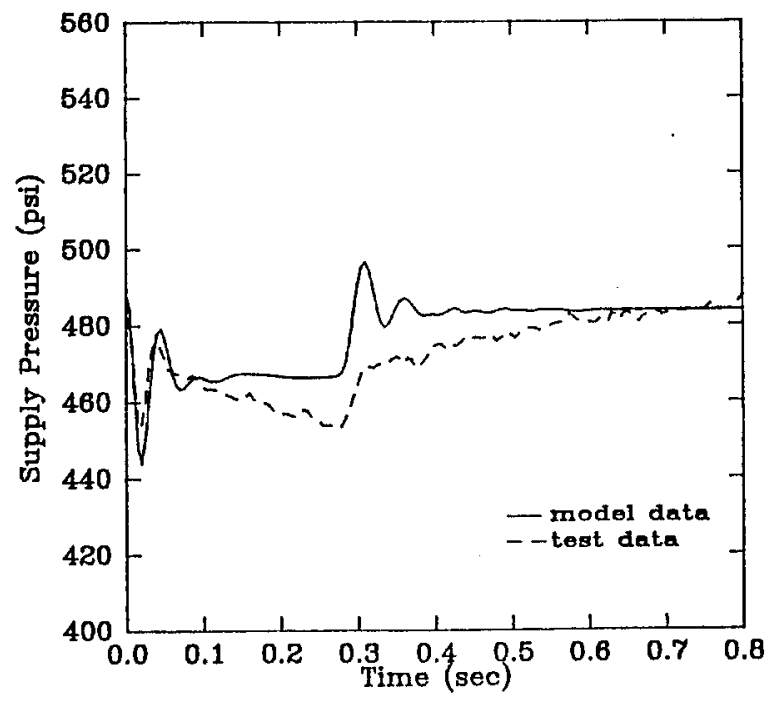

Figure 17. Supply Line Pressure vs. Time.

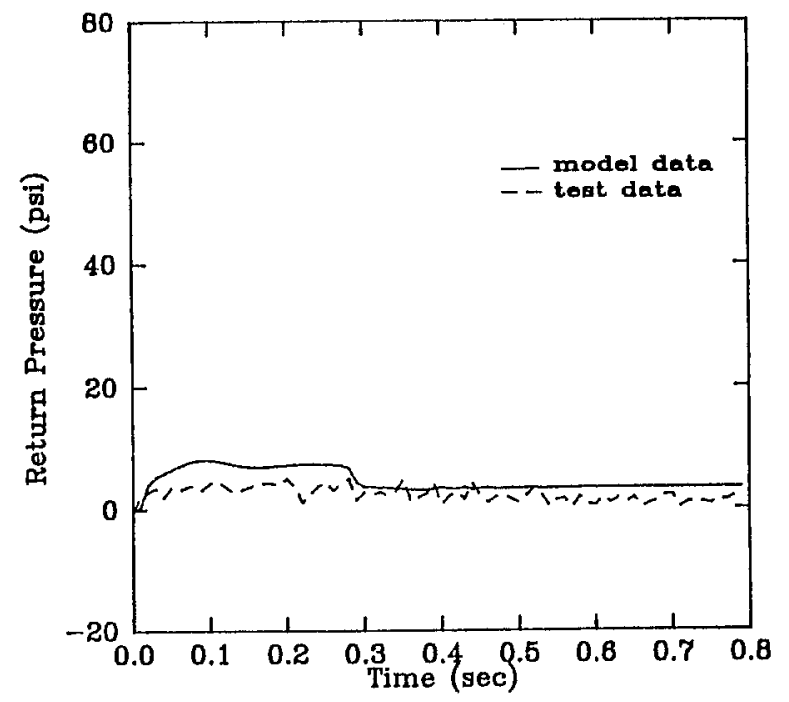

Figure 18. Return Line Pressure vs. Time. compliance effects and laminar flow in the lines. In reality, the compressibility of hydraulic fluid can be dramatically affected by entrainment of air in the fluid as it flows through the system. While laminar flow developed in the fluid lines, turbulence was certainly introduced into the system because of fittings and other such obstructions. Differences between the model and test data for supply pressure and return pressure (Figures 17 and 18) are due to the assumption made that the supply and return pressure sources were ideal and that they did not fluctuate in time. While these differences are significant, the focus of this effort did not concern the hydraulic power supply dynamics and therefore, they were not addressed.

\section{SUMMARY AND CONCLUSIONS}

The construction of a lumped parameter model with nonlinear elements of a hydraulic actuation system has been described. The accuracy of the model was made possible by the detailed modeling of nonlinear elements (hysteresis, saturation, orifice area relations, signed quadratic pressureflow relation, etc.). The usefulness of the model for the analysis and design of electrohydraulic valves and hydraulic actuator systems has been demonstrated and is discussed in a forthcoming paper.

\section{ACKNOWLEDGEMENTS}

The authors are grateful to the Naval Ocean Systems Center for the support of this research through NOSC contract \#N66001-87-C-0117.

\section{REFERENCES}

[1] Nikiforuk, P.N., Ukrainetz, P.R., and Tsai, S.C. "Detailed Analysis of a Two-Stage Four-Way Electrohydraulic Flow-Control Valve," J. Mech. Eng. Sci., Vol. 11, No. 2, 1969.

[2] de Pennington, A., 't Mannetje, J.J., and Bell, R. "The Modelling of Electrohydraulic Control Valves and Its Influence on the Design of Electrohydraulic Drives," J. Mech. Eng. Sci., Vol. 16, No. 3, 1974.

[3] Martin, D.J. and Burrows, C.R. "The Dynamic Characteristics of an Electrohydraulic Servovalve," Trans. ASME, J. Dyn. Sys., Meas., Control, December, 1976.

[4] Shearer, J.L. "The Effects of Radial Clearance, Rounded Corners, and Underlap on Servovalve Characteristics," Proc. Joint Automatic Control Conference, 1980.

[5] Shearer, J.L. "Digital Simulation of a Coulomb-Damped Hydraulic Servosystem," Trans. ASME, J. Dyn. Sys., Meas., Control, Vol. 105, December, 1983.

[6] Jacobsen, S.C., McLain, T.W., Iversen, E.K., and Davis, C.C. "Effects of Design Parameter Variation on the Intrinsic Behavior of a Hydraulic Actuation System," a report submitted to the Naval Ocean Systems Center, contract \#N66001-87-C-0117, April 1989.

[7] Frame, J.G., Mohan, N., and Liu, T. "Hysteresis Modeling in an Electromagnetic Transients Program," IEEE Trans. on Power Apparatus and Systems, Vol. PAS-101, No. 9 September 1982.

[8] Blackburn, J.F., Reethof, G., and Shearer, J.L., ed. Fluid Power Control. Cambridge: The M.I.T. Press, 1960. pp.144-147, pp.300-304.

[9] ACSL Reference Manual. Mitchell and Gauthier Associates, Concord, Massachusetts, 1986.

[10] Rosenberg, R.C. and Karnopp D.C. Introduction to Physical System Dynamics. New York: McGraw-Hill Book Company, 1983. pp.175-186.

[11] Karnopp, D.C. and Rosenberg, R.C. System Dynamics: A Unified Approach. New York: John Wiley \& Sons, 1975.

[12] Janna, W. S. Introduction to Fluid Mechanics. Boston: PWS Engineering, 1983.

[13] Talukdar, S.N. and Bailey, J.R. "Hysteresis Models for System Studies," IEEE Trans. on Power Apparatus and Systems, Vol. PAS-95, No.4 July/August 1976. 